\title{
MOBILIÁRIO DE OFÍCIOS: AS BANCAS DE OURIVES SERVICE'S FURNITURE: THE OURIVES BANKS
}

\author{
Rosa Maria Dosantos Mota* \\ Universidade Católica Portuguesa- CITAR
}

\section{Resumo}

A peça de mobiliário conhecida como banca de ourives, que examinamos neste breve artigo, integrou as oficinas de ourivesaria, desde há séculos e até meados do século XX, e sobre ela se executavam grande parte das operações necessárias para a manufactura tanto de objectos de ouro como de prata. A estrutura das bancas de ourives portuguesas caracteriza-se pela sua simplicidade formal, utilizando-se na sua execução madeiras autóctones e outros recursos do próprio ambiente em que se construíram. Por isso, apresentam um manifesto carácter regional, enquanto mantêm linhas gerais estáveis, sóbrias e arcaizantes, comuns a todas as oficinas e regiões. A sua razão de ser encontrou justificação na adequação ao trabalho que sobre elas era executado, e ao local a que se destinavam, mas também às características do seu utilizador, que estabelecia com o móvel uma relação de estreita proximidade, sendo as bancas muitas vezes personalizadas tanto em pormenores técnicos como na adequação ao físico do seu usuário.

Palavras-chave: mobiliário, mobiliário de ofícios bancas de ourives, ourivesaria

\section{Abstract}

The goldsmith benches we will discuss in this article were used through centuries and until mid-twentieth century and were a piece of furniture used in the goldsmith workshops, serving as a support for the multiple tasks necessary to produce gold or silver ornaments. The structure of the portuguese goldsmith's benches is characterized by a formal simplicity, the use of local wood and other resources, showing, therefore, a very regional character, while presenting clean and archaic lines common to all workshops and regions. Their essence resided in the type of work for which they were created, the place for where they were built, but also in the link with the physical traits of the men who used them and the way they performed their craft.

Keywords: furniture, stalls, goldsmith stalls, goldsmith

\footnotetext{
*E-mail: rosamariamota@netcabo.pt
} 


\section{Tipos de bancas}

Além de palco para as mais variadas manifestações estéticas, o mobiliário exprime narrativas de períodos de vida das sociedades, traduzindo assuntos tão variados como gramáticas decorativas, mestria de execução, luxo, ostentação, poder, hierarquias, conforto, enquanto realizando a sua função utilitária. E se, em certo sentido, o mobiliário é inseparável da arquitectura, os móveis de carácter verdadeiramente funcional são indissociáveis dos usos para as quais foram criados, sendo dentro desta categoria que incluímos a peça de mobiliário sobre a qual nos debruçamos: as bancas de ourives.

Do século XV e XVI chegaram até nós gravuras ${ }^{1}$ registando oficinas de ourivesaria europeias, nas quais os ourives trabalham em longas mesas assentes sobre dois pés em X, ou sobre duas tábua direitas, unidos por uma trave de sustação a todo o comprimento da mesa. Colocadas contra as paredes da oficina ou no centro desta, sobre estas mesas corridas, sucessoras das longas arcas anterior ou simultaneamente usadas para o mesmo efeito e antecessoras das bancas, se executava o labor do ourives, sendo este móvel de trabalho comum e não individual.

Mas, noutras latitudes, o ouro não se trabalhava em mesas ou bancas e, por exemplo, na India, os ourives, da casta dos Sonars, trabalhavam sentados no chão, usando pequenos utensílios e suportes de madeira ou caixas com diminutos pés cuja utilização implicava que, também, se estivesse sentado no chão ${ }^{2}$. No Iémen, no século XIX, entre os ourives judeus, existia uma espécie de banca peculiar formada por um tipo de escritório "de estrado" adaptado nas dimensões e na forma à sua função que, por não ter suporte próprio, se pousava sobre um estrado de madeira onde os próprios ourives se sentavam.

Mas, de regresso à Europa, um outro tipo de móvel, além da mesa corrida, foi utilizado numa geografia alargada. Assim, serviram como bancas de ourivesaria mesas com o tampo recortado, formando reentrâncias para albergar um ourives em cada uma delas. Existiram também meias mesas deste tipo, com uma parte com reentrâncias e um topo liso para se encostar a uma parede, geralmente debaixo de uma janela. Sob as reentrâncias das mesas pendia uma espécie de saco em couro cuja finalidade seria a de aparar a escovilha, ou qualquer minúscula partícula das gemas que pudesse cair durante o trabalho. Nos séculos XIX e XX, encontrámos este sistema em Inglaterra, na França, na Suíça, na Suécia e na Rússia, mas não temos conhecimento da sua existência em Portugal. Este tipo de mesas deu origem a bancas individuais, duplas ou triplas com a mesma reentrância central, enclausurando o ourives, e duas plataformas laterais para suporte dos utensílios, que também não se usou em Portugal. No final do século XX algumas das bancas tradicionais apresentaram uma ligeira alteração em direç̧ão a este sistema, mas que se revelou de parca utilização. Seria apenas no século XXI, com a aplicação da ergonomia ao mobiliário, que este sistema se voltou a considerar, mesmo assim sem grande sucesso, continuando as bancas de frentes lisas a atrair a preferências dos ourives portugueses. 


\section{A banca tradicional portuguesa}

Rafael Bluteau, no seu dicionário, de 1728, descreve banca como sendo um bufete sobre o qual o letrado tem os livros em que estuda ${ }^{3}$, não a conotando com o trabalho artesanal. Em 1789, António de Morais define banca como uma espécie de mesa, tosca, lavrada com pouca curiosidade ${ }^{4}$ intensificando aqui a sua pouca qualidade de execução e decoração. Já no século XX, no Dicionário Houaiss da Língua Portuguesa ${ }^{5}$, banca é uma mesa grande e de qualidade inferior, mesa rústica ou improvisada, um estrado sobre cavaletes em que feirantes, mercadistas, vendedores ambulantes, etc, expõem os seus serviços, e os Dicionários Editora ${ }^{6}$ atribuem-lhe o significado de mesa rectangular e tosca. Nenhum deles associa a banca ao trabalho do ourives, ou de qualquer outro ofício como os carpinteiros ou os marceneiros que também usam uma banca na sua actividade profissional, e quase todos a definem como grosseira e de qualidade inferior, e, em todas as profissões mencionadas, ela é na verdade um sinónimo de mesa.

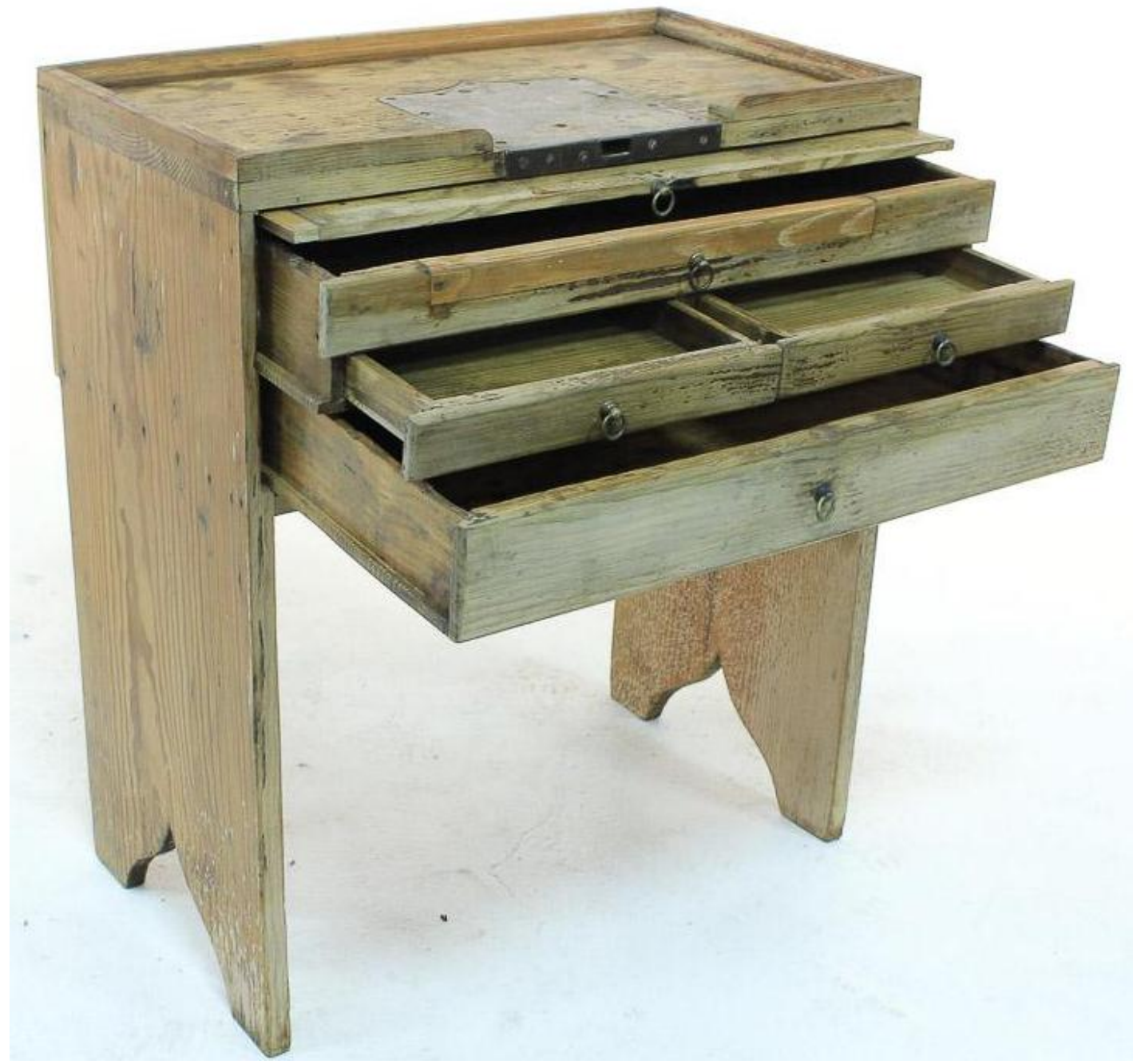

Fig. 1 - Exemplo de uma tradicional banca de ourives portuguesa, apresentando a tradicional divisão em duas gavetas, dois escaninhos e um estirador. Tampo com moldura e chapa de metal, ao centro. Ilhargas simples e vazadas ao fundo. Executada madeira de pinho e utilizada até meados do século XX. Colecção particular. 
A tradicional banca de ourives portuguesa consiste num móvel de carácter absolutamente utilitário, de aspecto robusto, com uma constituição técnica muito simples, parca decoração, adequada ao espaço para o qual foi concebida e executada em madeiras autóctones. Em termos formais é composta por uma caixa, ou "fábrica", na qual se inserem gavetas de número variável, mas, geralmente duas gavetas, uma das quais em caixa dupla e onde se inserem dois escaninhos, sustentada por duas ilhargas ou por ilhargas e quatro pés, em menos espécimes (Fig.1). Os encaixes das gavetas e do corpo da banca constituem-se por juntas de malhetes em forma de cauda de andorinha, naquelas de melhor qualidade e executadas por marceneiros, ou simplesmente por uma construção de tábuas em que a parte da frente e de trás são pregadas aos lados com pregos de ferro, numa construção como as das caixas de tipo medieval ${ }^{7}$, e, neste caso, executadas por carpinteiros. Porém, mesmo nos exemplares mais requintados, a robustez e o seu carácter anacrónico aproximam-nas do mobiliário medieval e, dessa forma, Bernardo Ferrão compara um escritório seiscentista a uma banca de ourives da região portuense que, tendo sido usadas ate meados do nosso século [século XX], mantiveram sempre uma arcaizante linha gótica ${ }^{8}$, opinião com a qual concordámos. Para compreendermos este simples e eficaz móvel procederemos a uma análise de cada um dos seus componentes, separando cada um deles por tópicos, de forma a optimizar a leitura e a compreensão.

\section{a. O tampo}

O tampo de todas as bancas apresenta-se liso e rematado com um perfil de madeira, cuja função consiste apenas em evitar que os objectos pousados sobre si caiam ao chão, e não tendo qualquer utilidade na sustentação do móvel. Na frente do tampo, ao centro, este perfil é interrompido para possibilitar o trabalho do ourives, que se executa sobre uma chapa de metal aí colocada, e que assume formas diferentes em cada banca, de acordo com o gosto e a vontade do ourives. Esta peça, não tendo uma função na estrutura da banca, revela-se extremamente importante para o trabalho do ourives que necessita de uma superfície lisa para executar o seu trabalho. Dadas as características perecíveis da madeira, dos veios que a constituem, passível de se desgastar com o tempo, abrir golpes ou se queimar com o maçarico, o tampo de madeira da banca não poderia satisfazer este requisito por muito tempo, daí a extrema utilidade da chapa de metal ${ }^{9}$.

No centro desta placa e do tampo de madeira encaixa-se a estilheira, um bloco de madeira de forma rectangular, amovível, e que constitui um componente fundamental deste móvel, pois serve de apoio para a mão e a ferramenta das várias operações necessárias para a execução de uma jóia, tais como limar, serrar, polir e engastar. Por vezes, o uso constante da estilheira levava a que o tampo se deteriorasse no local onde esta encaixava, permanecendo em bom estando na parte de trás. Nestes casos, a chapa de metal era levantada e o tampo girava-se, voltando-se a colocar a chapa no seu lugar e a ajustar o perfil conforme as novas alterações, para aproveitamento do tampo, evitando a sua substituição, operação mais dispendiosa. 


\section{b. As costas, as ilhargas e os pés}

As costas da banca, geralmente lisas, nos exemplares de melhor qualidade reflectem o tipo de decoração das frentes, não sendo comum o uso de madeira de refugo para esta parte da peça e sim a utilização da mesma madeira de toda a banca.

Por sua vez, a maioria das ilhargas apresenta-se lisa, mas existiam exemplares nos quais uma moldura enquadrava a parte superior desta peça, conferindo-lhe um maior esmero decorativo. Esta solução parece ter sido pouco utilizada, pois a grande maioria delas apresenta-se plana. $\mathrm{O}$ apoio inferior da ilharga é sempre recortado em vazado ${ }^{10}$ com formas variadas e, em muitos casos, a repetirem a configuração da chapa de ferro do tampo. A forma destes cortes e a precisão com que foram executados constituem indícios da perícia do carpinteiro que os fez. Na recolha exaustiva a que procedemos, encontrámos tipos de formas vazadas que se repetiam: terminação em arco quebrado e arco abatido que chamam em cauda de andorinha, em triângulo, em meia-lua ou arco abatido, formatos extravagantes combinando duas formas geométricas, lembrando os arcos trilobados e vazados toscos. Num dos exemplares estudados (ver ilharga da banca da Fig.3) deparámo-nos com uma abertura em cauda de andorinha com os lados diferentes, situação provavelmente motivada pela falta de perícia do executante do móvel que impossibilitou a realização dessa forma perfeita. Se, por um lado, tais pormenores revelam a ineficácia do carpinteiro ou ourives/carpinteiro, por outro comprovam a grande ligação que existia entre a execução deste móvel e do seu futuro usuário. Alguns modelos não apresentam ilhargas até ao chão, mas simples pés.

\section{c. Gavetas e estiradores}

Sob o tampo, na maior parte dos modelos, esconde-se um estirador, mas que é opcional. A gaveta de cima, geralmente, é de caixa dupla para conter duas gavetas mais pequenas, os escaninhos, que se destinam a conter instrumentos de trabalho, peças, notas e utensílios que o ourives considere relevantes para o seu ofício. Por isso, a sua distribuição nem sempre é a mesma, dependendo da vontade do ourives e da forma como encontra mais prática a colocação dos seus apetrechos, encontrando-se exemplares com poucas divisões e outros com inúmeros pequenos repartimentos. A gaveta de baixo, à por vezes designada por gavetão, assume a mesma função das peças de couro das mesas ovaladas feridas supra, ou seja, serve para apanhar todas as partículas dos metais ou gemas com que se está a trabalhar e, por isso, encontra-se sempre aberta durante o trabalho. Para optimizar essa função a gaveta é completamente forrada a metal no seu interior, uma vez que a madeira permitiria a absorção de partículas de escovilha nos seus veios, impossibilitando a recuperação dos pós metálicos. 


\section{d. Segurança das bancas}

Algumas bancas possuíam" segredos", pequenas gavetas ou esconderijos que só se abriam recorrendo a formas apenas conhecidas do ourives. Tais compartimentos secretos funcionavam como um cofre e a própria banca também tinha um sistema de segurança - as trancas -, que caiu em desuso com o tempo (Fig.2). A tranca consistia num arco de ferro dobrado ao meio num arco mais ou menos fechado e, que, por vezes, repetia a forma da chapa de metal do tampo e do vazado da ilharga e cujas extremidades encaixavam em duas argolas do mesmo metal imbuídas lateralmente na banca aquando da sua construção. $\mathrm{O}$ centro deste arco encaixava no local da estilheira, depois desta retirada, sendo fechado com um aloquete de ferro. Depois de cerrado o arco impedia que todas as gavetas se abrissem e esta utilização da ferragem - guardar em vez de adornar-, será mais um elemento arcaizante presente nestes móveis de oficina.

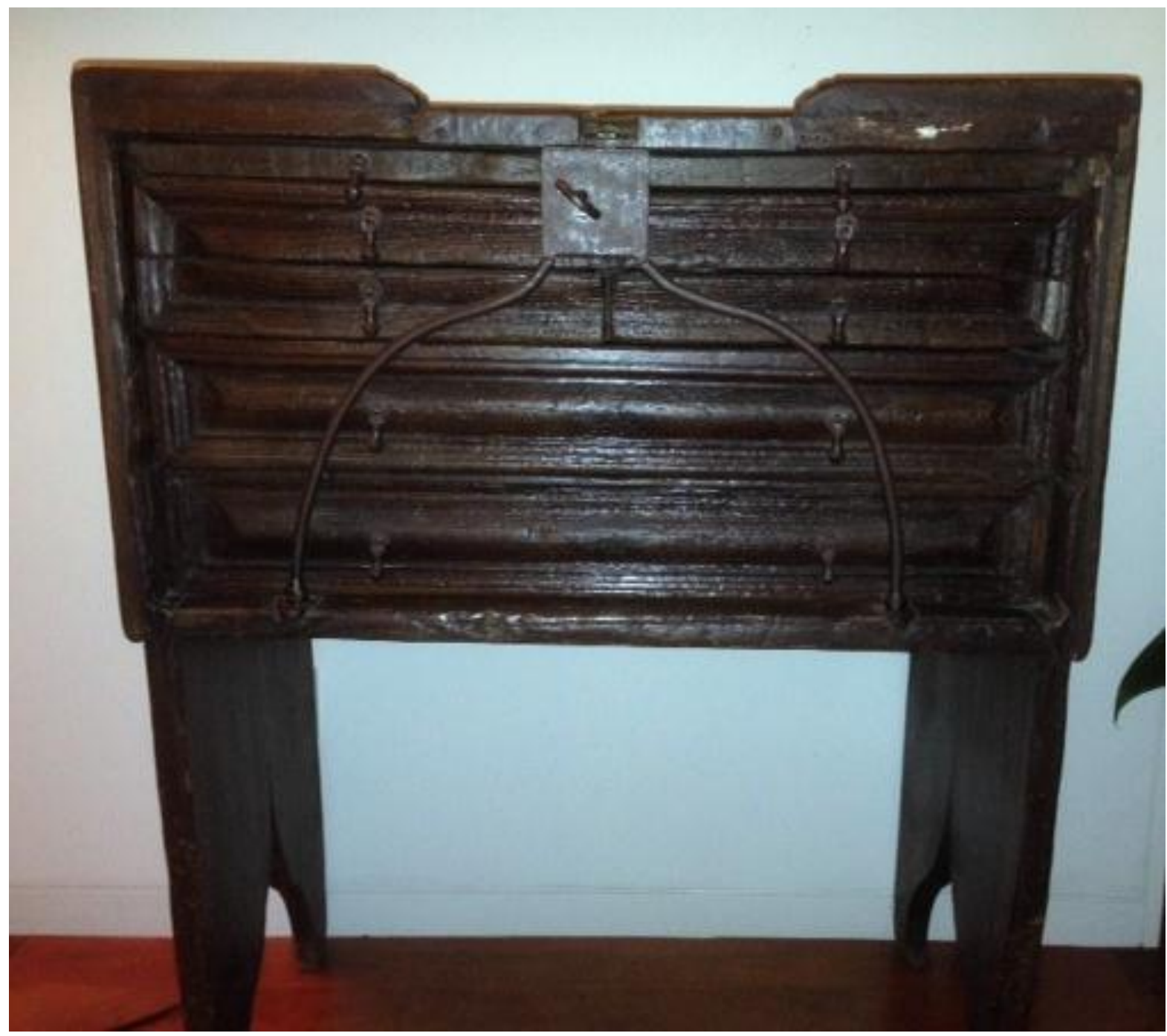

Fig.2. Exemplo de banca com tranca - arco de ferro e fechadura -, sistema de segurança caído em desuso com o tempo. Colecção de Manuel Alcino. 
Os elementos referidos constituem a banca clássica portuguesa. Nos séculos XVIII e XIX, existia uma maior variedade de bancas, pois quase todas eram executadas segundo especificações do próprio ourives e, nalguns casos, por eles mesmos. Em certas oficinas de Travassos ${ }^{11}$ ter permissão para executar ou delinear a sua própria banca poder-se-ia equiparar à prova de passagem de aprendiz a mestre, e considerava-se um acontecimento de prestígio para o ourives dentro da oficina e entre os seus congéneres. Durante a primeira metade do século XX, usam-se bancas já existentes ou, carpinteiros locais, reproduzem os modelos conhecidos, levando a uma uniformização do móvel. Contudo, em termos de "fabrica", existem diversas soluções, com várias gavetas e escaninhos, encontrando-se, por exemplo, bancas todas semelhantes na mesma oficina e diferentes noutra, e quase que se poderia dizer que existem tantos tipos de bancas como ourives!

\section{Matéria-prima, dimensões, bancas de características especiais e elementos simbólicos}

Os lenhos eram escassos num território limitado pelo crescimento das árvores quase unicamente a Norte do Tejo e, para além das condições climáticas, o factor humano foi determinante na evolução das florestas. Assim, por exemplo, no Norte de Portugal, a casa beneditina de Tibães foi uma das instituições que se preocupou com a reflorestação, permitindo que a construção retabular e o mobiliário tivessem à sua disposição matéria-prima diversa, por exemplo, madeira de castanheiro ou pinho de riga. Num tempo em que as vias de comunicação eram problemáticas, sobretudo em zonas montanhosas, e a navegabilidade dos rios apresentava muitas restrições, o natural seria que os marceneiros utilizassem a matéria-prima disponível na sua zona de actuação ${ }^{12}$. Dessa forma, as bancas de ourives, ao longo dos séculos, foram executas em madeiras diferentes, mas sempre endémicas das regiões onde a ourivesaria se desenvolvia. Nos exemplares que estudámos, a casquinha, o carvalho e o pinho surgem em bancas do século XVIII e XIX. Neste último século o pinho já é o mais utilizado e, no século XX, constitui a matéria-prima da maior parte das bancas, existindo, também, alguns exemplares em castanho. A qualidade da matériaprima acompanha as características do móvel, daí que o pinho, por se revelar, barato, fácil de encontrar, de trabalhar e suave ao toque, seja a madeira eleita no último século. Quanto ao carvalho, muito usado no Minho, revelava-se também uma óptima solução, pois é uma madeira dura, leve, resistente e durável embora mais cara, o que limitaria o seu uso nestes móveis de oficina que se queriam eficazes e duráveis, mas não dispendiosos.

As dimensões das bancas individuais variam de modelo para modelo. A altura média para uma mesa é de $75 \mathrm{~cm}$, porém, as bancas que elencámos variavam entre os $70 \mathrm{c}$ e os $87 \mathrm{~cm}$. Sendo mais as bancas acima dos $75 \mathrm{~cm}$ do que abaixo desta medida. Estas alturas muito acima da média do usual para mesas devem-se ao facto de os ourives trabalharem sempre com a última gaveta aberta, daí a necessidade de espaço suficiente para encaixar as pernas no vão formado 
pela caixa e ilhargas. Era comum que na mesma oficina todas as bancas tivessem a mesma altura, pois estariam alinhadas uma a seguir às outras, formando uma plataforma de trabalho continua e uniforme, servindo a altura do banco para regular o acesso do ourives á superfície de trabalho. $\mathrm{O}$ comprimento variava entre os 55 e os $90 \mathrm{~cm}$, sendo os $60 \mathrm{~cm}$ a medida média. A profundidade variava entre os 26 e os $40 \mathrm{~cm}$, não sendo muito importante pois a gaveta de baixo aberta acrescenta profundidade ao tampo da banca. Parece-nos que a dimensão e importância da oficina para a qual eram executadas, a também a estrutura física do ourives, e a sua importância dentro da estrutura oficinal constituíam elementos importantes nas medidas destes móveis.

Além das bancas individuais existiam bancas duplas e triplas e, ainda, bancas individuais com medidas fora do comum. Encontrámos um exemplar com $122 \mathrm{~cm}$ de largura, o necessário para uma banca dupla, mas apenas com uma chapa de metal, o que implica o uso por apenas um ourives, e que, certamente terá sido feita segundo esse requisito especial. Existiam também bancas com características especiais, motivadas pelas condições económicas ou espaciais da oficina. Assim, deparámo-nos como uma tosca banca de pinho, de uma pequena oficina, na qual se adaptaram duas chapas de metal para permitir o trabalho de dois homens, sendo a segunda chapa ainda mais rudimentar do que a original. A grande maioria das bancas, senão a totalidade, executavam-se para um local específico, por isso, muitas delas apresentavam características que visavam colmatar defeitos das paredes contra as quais se iriam encostar. Assim, se a parede da oficina estive fora de esquadria, um dos lados da banca seria também executado da mesma forma para que, uma vez unidos, fosse possível uma junção perfeita dos dois elementos, como se revela numa das bancas encontradas numa oficina agora transformada em centro museológico ${ }^{13}$. Na mesma banca, a interrupção da moldura na frente, e a colocação da chapa de metal, não acontece ao centro da banca, mas um pouco sobre o lado direito, pois de outra forma, por se encontrar sentado muito junto de uma parede o ourives teria os seus movimentos dos seu braço esquerdo dificultado, o que se reflectiria na qualidade do seu trabalho.

A expressão rústica, tosca e prática deste mobiliário utilitário, vernacular e oficinal - porque serve um ofício - torna a banca de ourives numa peça simples que, na sua maioria, se apresentava desprovida de qualquer elemento decorativo. Porém, a análise dos seus processos criativos mostra que a fantasia não está isenta dos seus corpos, surgindo em estriados horizontais e molduras que animam as frentes das bancas de melhor execução técnica. Seria, porém, na chapa metálica do tampo que a imaginação do artesão se soltaria e, por vezes, algumas delas, ultrapassam a simples meia-lua ou quadrado e exibem formas arquitectónicas caprichosas coroadas por pináculos, a lembrar janelas e portais góticos. Quase todas as chapas de metal, assim como os vazados das ilhargas, com que, por vezes, concordam, transmitem uma nota artística de carácter nitidamente goticizante dado pelas formas de arco abatido, arco quebrado, arco em chaveta e arco ultrapassado de volta inteira que aparecem já no mobiliário medieval. 
Também as ferragens das gavetas, nalguns exemplares, ultrapassavam a sua funcionalidade, enriquecendo as bancas com elementos decorativos, se bem que os ferros das trancas se apresentavam sempre simples e robustos, como convinha à segurança.

$\mathrm{Na}$ investigação que levámos a cabo, não encontrámos gravadas quaisquer formas propiciatórias como as que aparecem, por exemplo, nos barcos, nos jugos dos bois, nas portas das casas das aldeias e no mobiliário rústico. Apenas nos deparámos com a utilização de um elemento simbólico, a forma de arco quebrado e arco abatido a que os ourives chamam em cauda de andorinha e que muitos deles considerariam símbolo de boa sorte. Por isso, essa forma se encontra tantas vezes repetida nas chapas de metal no tampo da banca e nos remates vazados das ilhargas.

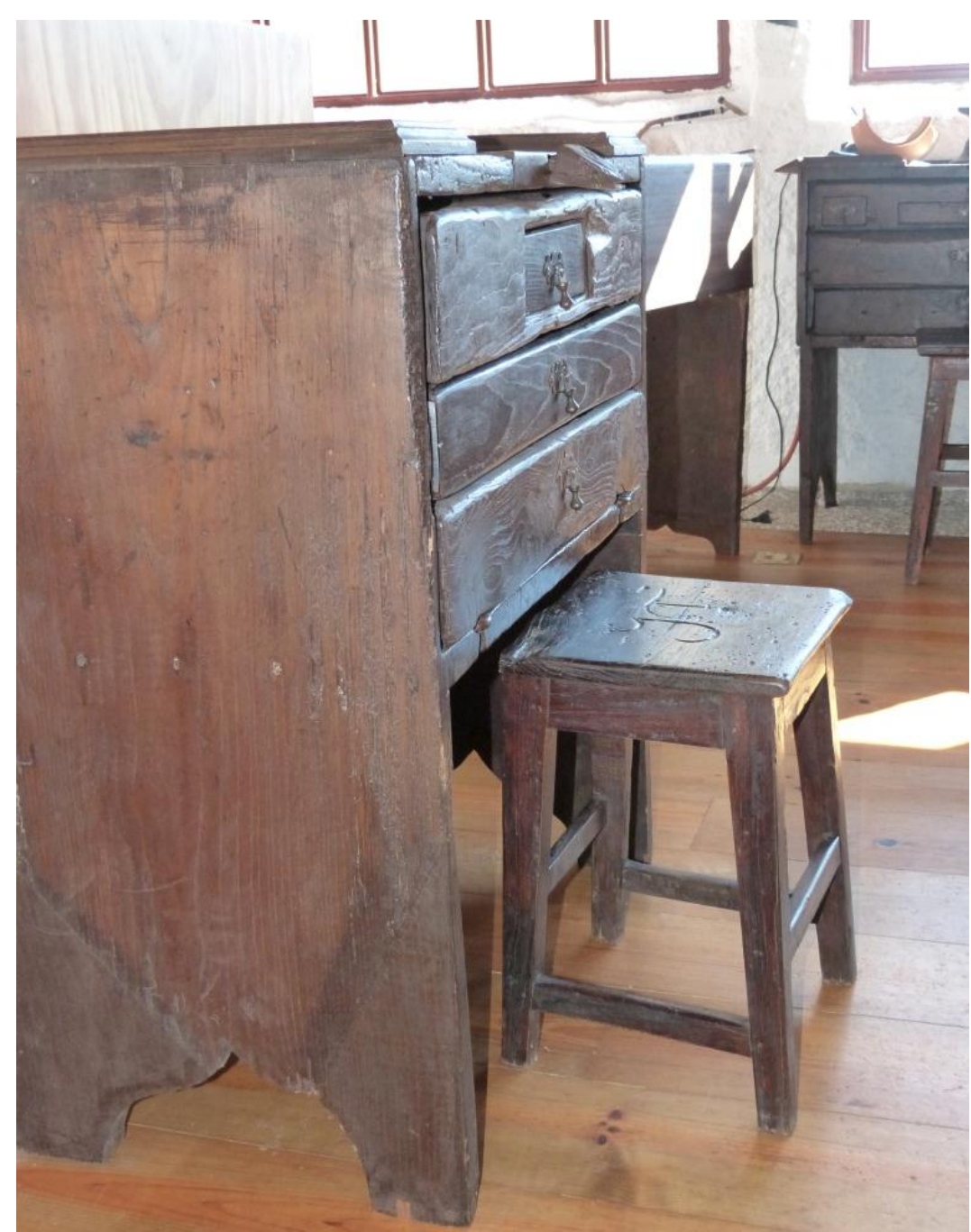

Fig.3. Banca de ourives com o banco que lhe pertencia, sendo este decorado com as iniciais do nome do seu usuário, identificando-o individualizando-o. Colecção do Museu do Ouro de Travassos. 


\section{Os móveis de assento da banca}

Indissociável da banca está o móvel de assento sem costas, o humilde banco. Geralmente tratava-se de um assento extremamente simples com um tampo e quatro pés, por vezes substituídos por quatro ilhargas rematadas ao fundo pelas mesmas formas vazadas da banca com a qual faziam par. Os modelos mais simples possuíam um orifício central em forma de "s" para facilitar o seu transporte. Esta peça de mobiliário revela-se extremamente pessoal, uma vez que deveria ser adaptada à altura do ourives, e era de uso intransmissível, sendo, muitas vezes, decorada com as iniciais do nome do seu usuário ou um símbolo que o identificasse, individualizando-o (Fig3). Dada a grande utilização que esta peça sofria, as características perecíveis da madeira e o facto de muitos terem sido trocados por cadeiras sem braços, mas mais confortáveis, muito poucos bancos chegaram até nós.

\section{Conclusão}

Votadas ao ostracismo, enquanto tema de investigação, as bancas de ourives não constituíram tópico de pesquisa por parte daqueles que se dedicam a estudos no campo da ourivesaria - nos quais apenas se consideram as peças, os dado biográficos, os contractos, os metais, até os instrumentos, mas nunca as bancas -, nem por investigadores de mobiliário, talvez pela sua extrema simplicidade formal, decorativa e simbólica. Daí a dificuldade em encontrarmos referências bibliográficas alusivas ao assunto e termos optado por uma análise do maior número de bancas que conseguimos encontrar, tanto em espécimes vistos em fotografias como observados presencialmente. Para o efeito, consideramos de extrema importância as fontes orais que consultámos desde ourives a escolas de ourivesaria, passando por carpinteiros, restauradores de mobiliário e antiquários.

Utilitárias, austeras, simples, por vezes toscas, arcaicas, de proporções estáveis, com ferragens usadas como segurança e não como enfeite, com diminuta utilização da simbólica, lembrando arcas ou escritórios aos quais se adicionaram pés, as bancas de ourives portuguesas atravessaram séculos, até meados do século XX. Por essa época, este mobiliário utilitário e oficinal enfrentou o abandono, mas também uma forma de sobrevivência e uma ressinificação. Assim, reinventando-se e reconfigurando-se, as bancas passaram a ser utilizadas como peça museológica, como peça integrada na decoração de casas de habitação e, ainda, como presença inalterável em muitas oficinas de ourives. Se, em alguns casos, se continua a trabalhar nestas quase obsoletas bancas por falta de meios para investir em modelos actuais, noutros é a ligação com estes modelos atávicos que predomina, e o facto de continuarem a servir o seu propósito, e, nas oficinas que optaram por mobiliário actual, são as tradicionais linhas rígidas que se continuam a encontrar nas bancas modernas, nas quais apenas a matéria-prima e a construção mudou. 
Baseadas num esquema formal simples, as bancas de ourives portuguesas reflectem as necessidades do ofício para o qual foram criadas e as matériasprimas autóctones, e mantiveram-se estáveis na sua configuração e função. Dessa forma, à primeira vista, estes simples móveis parecem todos iguais e destituídos de marcas identitárias individuais. Contudo, uma observação mais cuidada mostra as alterações na configuração de modelo para modelo, tanto sincrónicas como diacrónicas, principalmente ao nível da "fabrica", motivadas pelo seu usuário ou dono da oficina, afirmando a identidade cultural do meio em que se conceberam e se inseriram, e acarretando em si a essência do mester que serviram e dos homens que as criaram.

\section{NOTES}

\footnotetext{
${ }^{1}$ Ver, por exemplo, as gravuras o Master of Balaam, propriedade do Rijksmuseum, de Amsterdam, do século XV e a de Étienne Delaune, representando uma oficina em 1576. Na primeira gravura, o próprio Santo Elói, padroeiro dos ourives, é retratado a trabalhar na arte da ourivesaria, sentado num trono, e ostentando a mitra, uma das suas insígnias de bispo. Também na pintura do alemão Niklaus Manuel, de 1515, Santo Elói aparece a trabalhar os metais preciosos, desta vez sem a mitra, mas com um halo de luz ao redor da cabeça, dignificando a sua santidade.

${ }^{2}$ Este segundo sistema ainda hoje se encontra, ainda, na Ilha de Moçambique, junto de ourives de ascendência indiana e muçulmana que deles também herdaram os utensílios e as técnicas.

${ }^{3}$ Vd. BLUTEAU, Raphael, Vocabulario portuguez \& latino: aulico, anatomico, architectonico... Coimbra, Collegio das Artes da Companhia de Jesu, 1712 - 1728. 8, p.27.

${ }^{4}$ Vd. SILVA, Antonio Moraes. Diccionario da lingua portugueza - recompilado dos vocabularios impressos ate agora, e nesta segunda edição novamente emendada e muito acrescentado, Lisboa, Typographia Lacerdina, 1813, p. 257

${ }^{5}$ Vd. Dicionário Houaisss da Lingua Portuguesa, Lisboa, Círculo de Leitores, 2002, p.506

${ }^{6}$ Vd. Dicionário da Língua Portuguesa, Porto, Porto editora, p.204

${ }^{7}$ Vd. OATS, Phyllis Bennett, Historia do Mobiliário Ocidental, Lisboa, Editorial presença, 1991, p.41.

${ }^{8}$ Vd. FERRÃO, Bernardo, Mobiliário Português, Porto, Lello e Irmão - Editores, 1990, p.37.

${ }^{9} \mathrm{Na}$ maior parte das bancas actuais todo o tampo é revestido a metal, de forma a aumentar a superfície de trabalho e a durabilidade do tampo.

${ }^{10}$ As ilhargas poderiam não exibir este recorte, mas é tradicional fazê-lo em todos os móveis porque o soalho sobre o qual vão assentar nem sempre é uniforme e com dois pontos de sustentação consegue-se um equilíbrio maior do que se toda a ilharga tocasse o pavimento. Além disso, convém que os pontos de contacto com possíveis focos de risco de humidade sejam os menores possíveis, também daí o corte inferior da ilharga em vazado.

${ }^{11}$ Travassos é uma localidade no concelho de Póvoa de Lanhoso e no distrito de Barga onde a ourivesaria está fortemente implantada desde há vários séculos.

${ }^{12}$ Vd. VALENTE, Maria Adelina Nogueira, Matrizes inglesas no mobiliário português da segunda metade do século XVIII, Tese para obtenção do grau de Doutor em Estudos do Património na Escola das Artes da Universidade Católica Portuguesa. Março de 2014. Texto policopiado, vol. 1, pp. 121-123.

${ }^{13}$ Museu do Ouro de Travassos.
}

Fontes electrónicas

http://www.bl.uk/onlinegallery/onlineex/apac/photocoll/s/019pho001000s52u04935000.html

(5 Setembro de 2016)

http://doismaisdoisigualacinco.blogspot.pt/2006/05/ourives.html (12 de Setembro 2016)

http://www.custojusto.pt/porto/equipamento/banca-de-ourives-pt-n-2-18479589 
(5 Setembro 2016)

http://www.cml.pt/cml.nsf/0/51a627f876b084b3802575e6004945a4!OpenDocument\&Start=121\&C ount $=1000 \&$ ExpandView\&Click $=(\underline{5 \text { Setembro } 2016)}$

http://www.bestnetleiloes.com/pt/leiloes/varios-88/movel-de-ourives (5 Setembro 2016)

http://www.mdsleiloes.com/leiloes/33/?page $=21$ (5 Setembro2016)

http://www.mdsleiloes.com/leiloes/34/?page=11 (7 Setembro 2016)

http://www.mdsleiloes.com/leiloes/37/?page=7\#product_329 (7 Setembro 2016)

http://972mag.com/reviving-the-spirit-of-yemens-jewish-goldsmiths/84900OLX

(7 Setembro 2016)

https://www.olx.pt/anuncio/banca-de-ourives-em-madeira-antiga-sec-xix-IDtQYeZ.html

(7 Setembro 2016)

https://www.olx.pt/anuncio/banca-de-ourives-estilo-antigo-com-sistema-de-trancar-gavetas-

IDw4Med.html (7 Setembro 2016)

http://oportunityleiloes.auctionserver.net/view-auctions/catalog/id/225/lot/69801

(7 Setembro 2016)

http://oportunityleiloes.auctionserver.net/viewauctions/catalog/id/225/lot/69801/?u

(5 Setembro 2016)

http://oportunityleiloes.auctionserver.net/viewauctions/catalog/id/162/lot/57767/?url=\%2Fviewauctions $\% 2$ Finfo $\% 2$ Fid $\% 2 F 162 \% 2 \mathrm{~F}$ ( 9 Setembro 2016)

http://porto.quebarato.com.pt/gondomar/maquinas-e-ferramentas-diversas-para

ourivesaria_2E027E.html (7 Setembro 2016)

Fontes orais

Clemente Fernandes, Travassos

CINDOR, Escola de Ourivesaria, Gondomar

João Vilares, Engenho \& Arte Escola de Joalharia Contemporânea, Porto

José Alberto Castro Sousa, Gondomar

Manuel Silva, Restauro de Mobiliário, Paços de Ferreira

Manual Amândio Vieira, MAVJóias, Travassos

Museu do Ouro de Travassos

Ourivesaria Tavares, Póvoa de Varzim

Irmãos Rodrigues, Travassos

Rosário Neves, Gondomar 